\title{
TAUHID SEBAGAI PARADIGMA DALAM PENDIDIKAN ISLAM
}

\author{
Sugito Muzaqi \\ Muzaqi0201@gmail.com \\ Universitas Narotama Surabaya
}

\begin{abstract}
The striking difference between the science of religion and general science makes the cause of disintegration, resulting in the dichotomy of education. First, Westerners say it is not scientific in the eyes of religion because the object is not empirical. Second, general science is sensory while the science of religion is a hallucination but the source of the Qur'an and Hadist so that the belief system is still not one hundred percent. Third, objective science in religion can not necessarily be studied by modern enthusiasts, requiring a scientific message that can assure the existence of the religious knowledge of its source from belief. To be able to collaborate between the science of religion with general science. Then, the author tries to draw the red thread that both science has a synergy if it can be practiced together, especially science of monotheism with general science. The linkage between the science can be positioned namely rahmaniyah, takamuliyah, syumuliyah, tawzuniyah, privilege, wasaliyah, rabbaniyah and uswiyah. So they understand that it can be made a tool to be united without any interests. The result of the above study then this Paradigm requires that all entities between Earth and Heaven, Empiric and Ghaib entities, are integrated in a balanced development of theory and practice of learning.
\end{abstract}

Key Terms: Tawhid, General Knowledge, Paradigm, Islamic Education

\begin{abstract}
Abstrak
Perbedaan yang sangat mencolok antara ilmu agama dengan ilmu pengetahuan umum menjadikan penyebab adanya disintegrasi, sehingga terjadi dikotomi pendidikan. Pertama, orang barat mengatakan tidak ilmiah dalam kacamata agama karena objeknya bukan empiris. Kedua, ilmu pengetahuan umum bersifat indrawi sedangkan ilmu agama bersifat halusianasi padahal sumbernya dari al Qur'an dan Hadist sehingga system kepercayaannya masih belum seratus persen. Ketiga, ilmu yang sifatnya objektif dalam agama belum tentu bisa dikaji oleh peminat kaum modern sehingga membutuhkan pesan ilmiah yang bisa menjamin tentang keberadaan ilmu agama sumbernya dari keyakinan. Untuk bisa mengkolaborasi antara ilmu agama dengan ilmu pengetahuan umum maka penulis mencoba menarik benang merah bahwa kedua ilmu tersebut mempunyai sinergi jika bisa diamalkan secara bersama terutama ilmu tauhid dengan ilmu umum. Keterkaitan antara ilmu tersebut bisa diposisikan yaitu rahmaniyah, takamuliyah, syumuliyah, tawzuniyah, istimroriyah, wasaliyah, rabbaniyah dan uswiyah. Sehingga mereka memahami bahwa it bisa di jadikan alat untuk bisa bersatu tanpa ada kepentingan apapun. Hasil dari kajian di atas maka Paradigma ini menghendaki agar seluruh entetitas antara Bumi dan Langit, entetitas Empirik dan Ghaib, terintegrasi secara seimbang dalm pengembangan teori dan praktek pembelajaran.
\end{abstract}

Kata Kunci: Tauhid, Pengetahuan Umum, Paradigma, Pendidikan Islam 


\section{A. Pendahuluan}

Era globalisasi pada saat ini manusia di tuntut untuk berlaku cerdas, adanya persaingan dalam merubah peradaban manusia maka suatu paradigma akan di ciptakan karena kalau tidak mempunyai inovatif maka kita akan tergilas dengan adanya perubahan zaman. Pertumbuhan ilmu dan teknologi begitu cepat dan mencengangkan sehingga manusia akan bertanya antara percaya atau tidak. Kemajuan dalam ilmu dan teknologi telah membawa kemudahan-kemudahan untuk mencapai derajat peradaban yang lebih maju dan modern. Akan tetapi kecendrungan-kecendrungan yang bersifat destruktif bagi manusia dan kemanusiaan ini menjadikan adanya dikotomi dalam ilmu umum dan ilmu agama. Kemajuan ilmu dan teknologi telah membawa jurang yang bisa menjebak manusia sendiri yaitu kehilangan makna dan tujuan sehingga manusia telah jauh dari akar keagamaan dan dikikis dari keterkaitan serta keterarahan kepada sang Khaliq.

Kenyataan yang sangat aneh dan menakutkan bagi orang tua yang masih memiliki iman dan sesungguhnya apa yang terjadi dalam dunia pendidikan? mengapa dalam dunia pendidikan sepertinya kurang memperhatikan aspek moralitas peserta didik ? Sardar melihat bahwa hubungan antara tokoh-tokoh muslim dan umat islam belum mampu memahami dan menjelaskan teks-teks al Qur'an dan Hadits serta bagaimana konsep pelaksanaannya dalam dunia nyata ini.

Untuk mengembangkan urgensi pengembangan tauhid dalam menintegrasikan nilai ${ }^{1}$ Kartanegara mengawali adanya dikotomi ilmu umum dan ilmu Agama. Selanjutya beliau menjelaskan dampak yang luas dan serius dari adanya dikotomi ilmu tersebut terhadap pengembangan berbagai disiplin diantaranya.

Pertama : menyangkut status keilmuan. Orang Barat mengatakan bahwa ilmu agama belum bisa disebut ilmiah karena suatu ilmu baru dikatakan ilmiah apabila objek-objeknya empiris. Sedangkan ilmu agama tidak bisa lepas dari hal-hal yang ghoib, bahkan meletakkan kepercayaan kepada yang Ghoib sebagai intinya. Hal ini ternyata banyak polemik dalam sistem pendidikan di Indonesia. Di sekolah-sekolah umum masih mengenal pemisahan-pemisahan yang sangat signifikan antara ilmu umum dengan ilmu agama yang seakan-akan hanya ilmu umum yang profan dan netral jika dilihat dari sudut pandang agama.

Kedua : adanya kesenjangan antara sumber ilmu umum dengan ilmu agama.

Dikatakan valid jika informasi yang diperoleh dari indrawi karena menurut mereka satu-

\footnotetext{
${ }^{1}$ Kartanegara, Mulyadi, Integrasi Ilmu Sebuah Rekontruksi Holistik, h : 9
} 
satunya sumber empirik adalah pengalaman yang nyata. Akal dan indrawi sifatnya spekulatif maka perlu dikontrol dengan positifistik. Adanya intuisi merupakan pengalaman yang menganggap adanya halusinasi bahkan ilusi belaka. Kebenaran yang mendukung dalam otoritas sumber yang dipakai untuk mencapai kebenaran dalam ilmu agama adalah al Qur'an dan Hadits. Pengetahuan yang didasarkan pada hati (intuisi ) di pandang sebagai sumber yang diperoleh dari cahaya Ilahi Robbi.

Ketiga : Objek ilmu yang sah dalam disiplin ilmu adalah menuntut objek-objek yang bisa diamati dan dapat diobservasi oleh indra. Maka ilmu yang mempelajari objek-objek yang tidak bisa diobservasi (objek non fisik) tidak dapat dikatakan ilmiah karena ilmu tersebut derajat keilmiahannya belum tercapai. Disatu sisi pendukung ilmu agama memandang bahwa ilmu agama melihat objek non fisik seperti Tuhan, Malaikat yang merupakan suatu kemulyaan yang sangat penting.

Keempat : adanya disintegrasi tatanan ilmu umum dengan ilmu agama. Kecendrungan dalam menfokuskan cabang-cabang ilmu pengetahuan seperti ilmu fisika dan sains yang lainnya dalam ilmu agama dikesampingkan yang menimbulkan asumsi bahwa ilmu agama fardu ain sedangkan ilmu umu fardu kifayah.

Kelima: Metodologi ilmiah, menggunakan metode observasi atau eksperimen yaitu pengalaman indrawi yang ketat shingga tidak lagi mempercayai metode rasional atau logis yang di pandang apriori, apalagi metode intuitif yang sering dianggap sebagai subyektif bahkan halusinatif. Campur tangan Tuhan baik terhadap benda mati atau benda hidup yang dilenyapkan sama sekali. Metode seperti ini sangat bertentangan dengan kaum agamawan yang mendasarkan kebenaran agamanya adalah otoritas wahyu.

Keenam: belum adanya integrasi antara pengalaman dengan intuisi sehingga pengalaman melegitimasi yang riil dari manusia dan belum bisa di wujudkan melalui sains dan pengalaman indrawi yang benar-benar objektif. Maka pengalaman intelektual, mistik, intuitif dan religius merupakan subyektifitas yang semena-mena. Sedangkan pengalaman mistik dan religius merupakan pengalaman yang sangat tinggi sehingga tak jarang mengabaikan pengalaman indrawi dan rasional.

Dari kasus di atas maka perlu dikaji bahwa posisi tauhid adalah sebagai paradigma pengembangan ilmu pembelajaran. Kajian ini dapat menganalisis dan mensintesis tafsir ayat ta'lim yang dikhususkan pada surat al Alaq dengan pendekatan Bayani dan selanjutnya pembahasan tauhhid diposisikan sebagai paradigma pengembangan ilmu dan pembelajaran. 


\section{B. Pembahasan}

Konsep paradigma pertama kali dikenalkan oleh Thomas Khun dalam bukunya The Structure of Scientific Ravolution (1962) bahwa perkembangan ilmu pengetahuan bukan terjadi secara komulatif, tetapi terjadi revolusi, istilah paradigma merupakan terminiologi kunci dalam model perkembangan ilmu pengetahuan. Menurut George Rotzer istilah paradigma ini tak kurang dari dua puluh satu cara berbeda-beda, dan karena Kuhn tidak menjelaskan apa itu sebenarnya yang dimaksud dengan paradigma.

Seorang Masterman mencoba untuk meredusir ke dua puluh satu konsep paradigma yang berbeda-beda itu menjadi tiga bagian diantaranya : paradigma metafisik, paradigma sosiologis, dan paradigma kontruk. Istilah paradigma metafisik adalah konsesus yang terluas dalam dalam suatu disiplin ilmu yang membantu membatasi bidang (scope) dari suatu ilmu sehingga demikian membantu mengarahkan ilmuwan dalam melakukan penyelidikan. Menurut Robert paradigma adalah suatu pandangan mendasar dari suatu disiplin ilmu tentangapa yang menjadi pokok persoalan yang semestinya dipelajari.

Pernyataan Rotzer ${ }^{2}$ lain pula dengan Khun dan Masterman, Ia mengemukakan bahwa paradigma adalah pandangan yang mendasar dari ilmuwan tentang apa yang menjadi pokok persoalan yang semestinya dipelajari oleh suatu cabang ilmu pengetahuan. Paradigma membantu merumuskan apa yang seharusnya dipelajari serta aturan-aturan apa yang harus diikuti dalam mengintepretasikan informasi yang dikumpulkan dalam rangka menjawab persoalan-persoalan.

Hasan Langgulung ${ }^{3}$ memetakan atas dua pengertian antara Khun dengan Rotzer tentang paradigma yaitu suatu kerangka teoritis atau mengamati dan memahami masalah masalah ilmiah dalam bidang suatu karangka teoritis atau cara pandang dalam memahami alam yang digunakan oleh sekelompok ilmuwan sebagai pandangan hidup (world view)nya, yg fungsinya sebagai lensa yang seterusnya para ilmuwan dapat menjelaskan masing2 persoalan-persoalan dan jawaban-jawaban ilmiah tehadap masalah tersebut. Menurut Kuntowijoyo $^{4}$ : analisis dari Kuhn Mode of Inquiry atau Mode of Knowing yg

\footnotetext{
${ }^{2}$ George, Ritzer, Sosiologi : Multiple Paradigm Science,

${ }^{3}$ Hasan Langgulung, 131

${ }^{4}$ Kuntowijoyo, Paradigma Islam : Intepretasi Untuk Aksi, h. 327
} 
direfleksikan melalui paradigma Al Qur'an yaitu suatu kontruk pengetahuan yg memungkinkan kita memahami realita sebagaimana al Qur'an memahaminya.

Dari berbagai macam definisi yang di kemukakan oleh para ahli maka dapat di simpulkan bahwa paradigma ilmu pengetahuan merupakan cara memahami dan menjelaskan pengetahuan yang lain dan dapat di integrasikan antara ilmu Umum dengan ilmu Agama yang bisa berdampak pada kemajuan peradaban manusia pada saat ini.

Dari penjelasan para ahli di atas maka penulis memberikan sebuah statement bahwa paradigma Tauhid adalah paradigma yang diangkat dari kajian ta'lim dan ditujukan pada surat Al Alaq dengan pendekatan Bayani Wahdy dan Tarbawi.

\section{Kajian Paradigma Tauhid dari Konsep Ta'lim}

Paradigma tauhid menjabarkan bahwa "nature and live "nature and live are a whole and integrated system which make God as the center "“ dan paradigma ini termasuk paradigma metafisik. Paradigma ini diangkat dalam kajian ta'lim pd surat al Alaq, hasil analisisnya bayany-wahdy-tarbawi, kontelasi makna pada surah tersebut sbb :

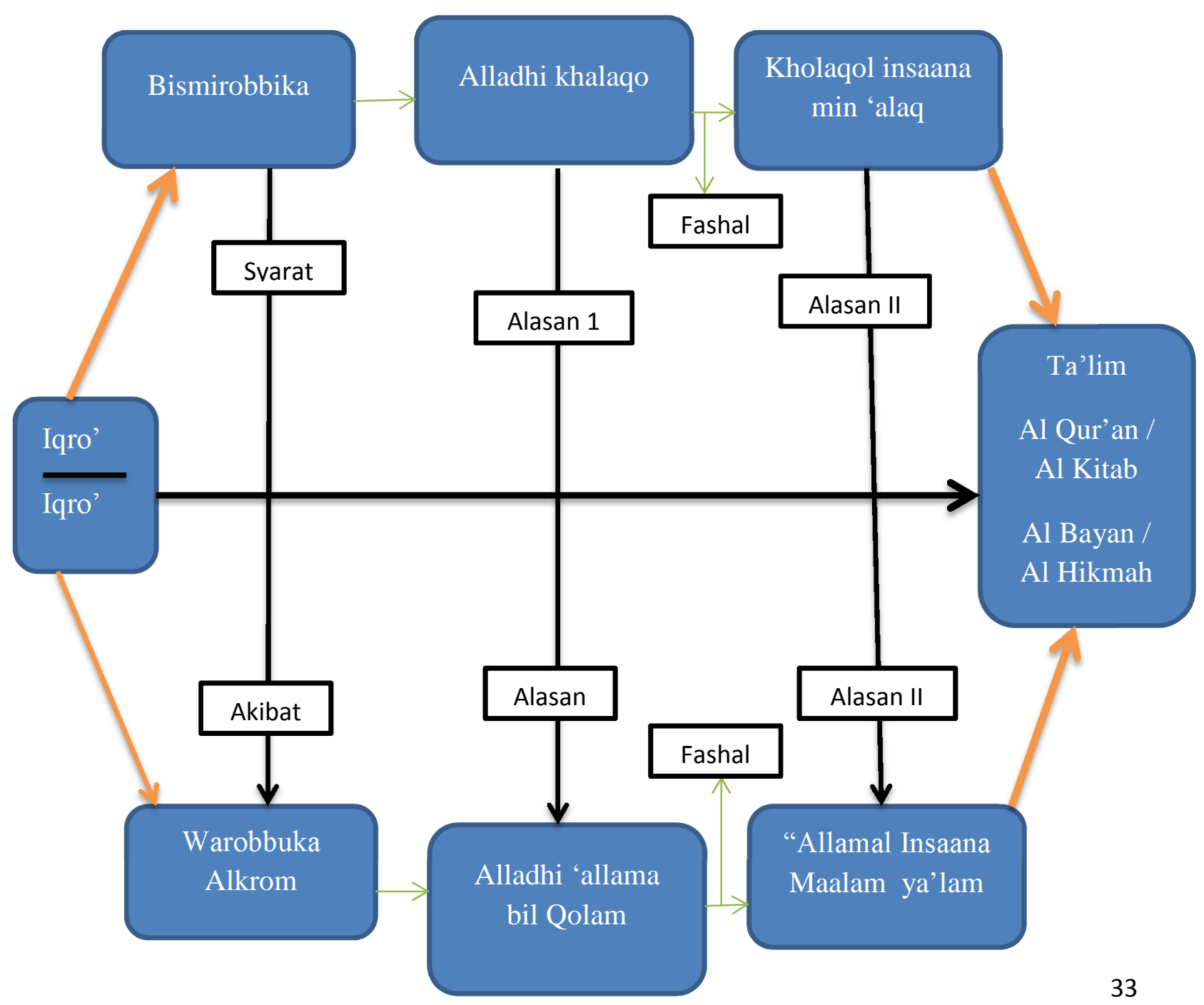


Penjelasan Bagan 01

1. Kajian bayani frase alladhi khalaqo dapat berkedudukan sebagai Illat (alasan) pertama dari kalimat sebelumnya, dan alasan kedua adalah Khalaqol insaana min 'alaqa, ini berarti bahwa dua ayat pertama merupakan seruan belajar dengan syarat menggantungkan dan mengarahkan aktivitas belajarnya kepada Robb, sebab Dia adalah satu-satunya pencipta dan manusia adalah makhluk yg tergantung penuh kepadaNya. Bagian ini menunjukkan urgensi belajar yang dikaitkan dengan eksistensi manusia yang penuh dengan ketergantungan atau menurut istilah eksistensi Rabb al Ghaniy (yang tak membutuhkan ) dan makhluk al Faqir (yg membutuhkan )

2. Warabbuka alkrom merupakan jawab (akibat) dari seruan belajar kedua, sedangkan alladhi 'allama bil qolam dan 'allamal insaana maa lam ya'lam menjadi illat kesatu dan kedua dr seruan belajar tersebut. Inipun menunjukkan urgensi belajar yang mengintegrasikan kehadiran dan keterlibatan Rabb. Jika belajar tersebut terintegrasi dengan nilai-nilai Rabb, maka akramiyah (kemuliaan dan segala nikmat serta kemurahan)Nya akan terungkap dan terkuak secara utuh, semua terjadi itu karena Rabb membelajarkan manusia (ta'lim) melalui sarana, media atau sumber belajar yang meliputi seluruh ilmu yang belum diketahui oleh manusia artinya : seluruh ilmu yang diperoleh dan diketahui manusia pada dasarnya merupakan hasil ta'lim Rabb kepadanya

3. Pada dasarnya Rabb membelajarkan (ta'lim) manusia melalui saran atau sumber belajar, tidak bersifat langsung. Maka Rabb memberikan dua sumber pokok dlm pembelajaran tersebut yaitu Al Qur'an (sumber yang di wahyukan ) dan al Bayani/ Hikmah ( sumber yang dikaji oleh manusia dari alam dan kehidupan, atau ayat qauliyah dan ayat ayat kauniyah

4. Iqra' pertama mengungkapkan urgensi belajar dengan bertumpu pada eksistensi Rabb sebagai satu satunya khaliq dan pada eksistensi manusia memiliki ketergantungan. Iqra' kedua mengungkapkan urgensi belajar dengan bertumpu pada eksistensi Rabb sebagai Muallim (pengajar belajar) melalui sarana, dan eksistensi manusia sebagai 
muallam (pembelajar). Integrasi 2 gugus ayat iqra' inilah yg menurunkan paradigma tauhid bagi pembelajar (ta'lim)

\section{Tauhid Sebagai Paradigma Pengembangan Ilmu dan Pembelajaran}

Pembahasan paradigma tauhid menjelaskan bahwa alam dan kehidupan merupakan satu sistem yang holistik dan integral yang menempatkan Tuhan sebagai satu-satunya sentral. Bagi orang beriman tidak ada keraguan untuk memaknai sentral tersebut. Muladhi menawarkan sebuah konsep rekontruksi pengembangan ilmu dengan prinsip integrasi. Ini muncul karena ada kekwatiran serius tentang sistem ekonomi yang semakin krosnis dan adanya dikotomi antara ilmu dan agama. Beliau menjelaskan bahwa sebuah rekontruksi holistik menawarkan satu prinsip utama yaitu prinsip tauhid. Konsep tauhid ini diambil dari rumusan Wahdatul Wujud dari Mulla Sadra. Dia menyatakan bahwa segala wujud yang ada dan segala bentuk serta karakternya pada hakekatnya adalah satu dan sama. Yang membedakan dari yang lain hanya gradasinya yang disebabkan karena esesnsinya. Oleh karena itu menurutnya ${ }^{5}$ wujud yang ada baik berwujud spiritual atau material yang dijadikan objek yang valid bagi ilmu.

Kuntowijoyo menawarkan paradigma al Qur'an yang bisa mengkontruk pengetahuan yang memungkinkan kita memahami realitas sebagaimana al Qur'an memahaminya. Pendekatan yang digunakan al Qur' an dalam mengangkat suatu paradigma adalah pendekatan sintetik analitik. Dengan pendekatan ini al Qur'an dibagi menjadi dua konsep yaitu kisah-kisah dan amsal (perumpamaan). Pendekatan sintetik memandang bahwa pengembangan archi-type dari sisi pesan moral yang bersifat abadi dan universal.

Sedangkan pendekatan analitik adalah memandang ayat-ayat al Qur'an sebagai pernyataan yang normatif yang harus diterjemahkan dan dianalisis serta di terjemahkan dari segi yang obyektif. al Qur'an merumuskan teori kontruk yang dielaborasikan dan menjadikan kegiatan al Qur'an teory building (perumusan teory al Qur'an yang disebut dengan paradigma qur'ani.

Struktur yang ada dalam al Qur'an mengenai bangunan idea yang sempurna mengenai kehidupan, al Qur'an sesungguhnya menyediakan kemungkinan besar untuk dijadikan cara berpikir yang transendental sehingga mampu melakukan penyingkapan alam melalui penelitian, eksperimen yang dapat dijadikan sebagai landasan filosofis yang bersifat

\footnotetext{
${ }^{5}$ Mulyadhi Integrasi Ilmu : Sebuah Rekontruksi Holistik h. 33
} 
normatif. Perumusan-perumusan yang disampaikan secara empiris akan digunakan sebagai kebijakan aktual.

Struktur transendental al Qur'an adalah sebuah ide normatif dan filosofis yang dapat dirumuskan menjadi paradigma teoritis. Ia akan memberikan kerangka bagi pertumbuhan pengetahuan yang empiris dan rasional serta orisinil, dalam arti sesuai dengan kebutuhan pragmatis masyarakat islam, yaitu untuk mengaktualisasikan misinya sebagai kholifah dimuka bumi ini. Oleh sebab itu teori-teori ilmu pengetahuan islam dimaksudkan untuk kemaslahatan umat manusia. Islam mewarisi sumbangan ilmu pengetahuan yang dihasilkan oleh peradaban lain demi pragmatisme. Pewarisan ilmu pengetahuan itu melewati proses islamisasi. Boleh diyakini bahwa kita dapat menemukan mekanisme untuk mengislamisasikan ilmu pengetahuan, yaitu bagaimana mengkonversikan dan menintegrasikan semua pemikiran dan warisan intelektual darimanapun ke dalam teoriteori yang di payungi oleh paradigma al Qur'an ${ }^{6}$

Hasan Langgulung mencoba mengembangkan paradigma islam tentang ilmu pendidikan dengan mengangkat konsep ummah. Paradigma Ummah adalah orde sosial dalam islam yang bersifat universal, meliputi semua ummat manusia tanpa terkecuali. Banyaknya suku-suku dan kelompok yang menyatakan standar kualitas eksistensi masingmasing kelompok sehingga keterarahan pada integrasi kepadaNya. Maksud dari ummah disini adalah pelaksana risalah ilahiyah seperti yang terkandung di dalam al Qur'an.

Antara paradigma tauhid, paradigma al Qur' an dan paradigma Ummah kesemuannya itu tidak jauh berbeda, suatu esensi yang dipandang sama dalam hal misinya. Menurut Hasan L. makna dan pemaknaan al Qur'an adalah nilai-nilai ilahiyah yang cara pandangnya holistik integralistik dan misinya mengembangkan ilmu dan kehidupan secara utuh, tidak dikotomis dan pragmatis. Paradigma tauhid yang diturunkan pada surat al Alaq oleh penulis disebut kekokohannya. Apalagi paradigma tersebut dikaji secara sintesisanalitis dari al Qur'an seperti yg di sebutkan oleh Kuntowijoyo.

Paradigma Tauhid berpandangan bahwa alam dan kehidupan merupakan sistem yang menyeluruh dan integral, yang menempatkan Tuhan sebagai satu-satunya sentral (the ultimate reality). Yang dimaksud dengan satu-satunya sentral adalah al Khaliq al Ghany (satu-satunya pencipta yang tak bergantung), sedangkan alam dan kehidupan adalah al makhluk al faqir (makhluk yang bergantung). Setidaknya ada dua pokok konsep dalam paradigma ini yaitu holistik-integralistik dan menempatkan Tuhan sebagai the ultimate

\footnotetext{
${ }^{6}$ Kuntowijoyo, Paradigma Islam: Interpretasi Untuk Aksi,: h. 335
} 
reality, dan apabila digabungkan antara sekuler dan dikotomistis tentang ilmu ini maka semua akan menjadi pragmentaris.

Ahmad Tafsir menyebut pada orang muslim bahwa untuk mengembalikan paradigma berpikir kepada nilai-nilai kehidupan yaitu iman (nialai-nilai agama). Keseriusan dan keberaniannya tersebut dapat terwujud dalam buku yang berjudul " Filsafat pendidikan Islam " dan "Ilmu Pendidikan Islam. Setelah belaiau menjelaskan tentang kehancuran budaya Barat akibat dari paradigma yang dikembangkannya.

Paham filsafat humanisme di kembangkan oleh orang Yunani pada tahun 600 SM. Humanisme adalah filsafat yang mampu mengatur terintegrasinya antara alam dengan kehidupan. Secara implisit Tuhan tidak campur tangan mengatur alam tetapi penggunaan humanisme dalam rasionalitas mengajarkan pada kebenaran yang terukur oleh rasio. Paham rasionalisme adalah paham positivisme yaitu paham yang ditentukan oleh rasio dan dibantu oleh bukti empirik. Paham inilah yang memunculkan metode ilmiah ${ }^{7}$ Perbedaan antara budaya Barat dengan Indonesia adalah terletak pada akal dan agama. Maka kebudayaan Barat buatan akal (manusia) sedangkan kebudayaan pancasila adalah kebudayaan buatan Tuhan Yang Maha Esa.

Dalam memantapkan urgensi pengembangan prinsip (paradigma) tauhid dalam integrasi nilai, Kartanegara ${ }^{8}$ ( 2005: 19) menjelaskan 6 permasalahan yang memerlukan pembenahan sebagai akibat dikotomi ilmu yang sekuler yaitu menyangkut status keilmuan, kesenjangan tentang sumber ilmu umum dan ilmu agama, objek ilmu yang dianggap sah sebuah disiplin ilmu, adanya disintegrasi pada tataran klasifikasi ilmu, masalah metodologi ilmiah, dan sulitnya mengintegrasikan pengalaman manusia, khususnya indra, intelektual dan intuisi sebagai pengalaman yang legitimasi dan riil pada manusia.

Menurut Kartanegara ${ }^{9}$ permasalahan yang melatarbelakangi pentingnya upaya pengintegrasikan nilai. Integrasi yang disarankan adalah melalui pengembangan dan pengalihkan konsep tauhid bagi pengembangan ilmu dan pembelajaran. Bukan kebetulan hal tersebut merupakan faktor penguat pentingnya paradigma tauhid tetapi dapat dikaji dari ayat-ayat tentang ta' lim disini. Kesenjangan-kesenjangan diharapkan dapat diselesaikan dengan pengembangan paradigma tauhid sebagaimana penulis rumuskan. Akan tetapi penulis tidak bermaksud untuk menjawab dan menyelesaikan masalah tersebut, sekalipun memang sangat berkaitan, bahkan merupakan konsekwensi logis daripadanya. Dari

\footnotetext{
${ }^{7}$ Abbs Mahmud, Filsafat Qur'an : filsafat, Spiritual dan Sosial dalam Isyarat al Qur'an,

${ }^{8}$ Mulyadi, Kertanegara (2005), Integrasi Ilmu: Sebuah Rekontruksi Holistik, h.13

${ }^{9}$ Mulyadi, Kertanegara, Integrasi Ilmu: Sebuah Rekontruksi Holistik, h. 19
} 
persoalan ini maka penulis akan mengevaluasi pada kajian sejauhmana peran tauhid menemukan relevansi dan signifikansi makna pada pengembangan konsep pembelajaran.

Pembelajaran adalah upaya untuk membelajarkan siswa. Pembelajaran ditekankan pada pengembangan metode dan rekayasa sumber pembelajaran atau media yang membantu mampu menumbuhkan semangat dan kreatifitas siswa untuk melakukan kegiatan pembelajaran secara mandiri. Harapannya siswa tetap belajar sekalipun guru tidak berada dalam kelas atau ruangan. Inilah yang membedakan pengajaran dan pembelajaran menurut Yudhi Munadi ${ }^{10}$ Sebagian ahli membedakan dari segi pengajaran yang lebih menekankan pada aktivitas guru dalam menyampaikan materi, sedangkan siswa hanya bertugas menerima. Berbeda dengan pembelajaran yang menekankan pada siswa bagaimana siswa dapat belajar dengan mandiri. Hal ini dapat dipahami oleh Corey dan Burton ${ }^{11}$ menyebutkan bahwa pembelajaran adalah proses dimana lingkungan seseorang dikelola untuk memungkinkan turut serta dalam aktivitas belajar atau dengan istilah lain upaya untuk memberikan stimulus, bimbingan pengarahan dan dorongan kepada siswa agar terjadi proses pembelajaran.

Konsep pembelajaran merupakan definisi pembelajaran yang paling banyak dikembangkan pada akhir periode ini, sebagai bentuk protes pembelajaran saat ini dituntut untuk mengembangkan dan mendorong siswa untuk aktif belajar secara mandiri. Dalam pelaksanaanya ada banyak teori yang mempengaruhi sistem pembelajaran diantaranya behavoristik, kognitif, kontruktivistik, humanistik, sibernetik dan banyak yang lainnya. Teori-teori ini muncul karena protes atau sebagai penyempurna atas teori pembelajaran sebelumnya. Dengan demikian teori baru ini tidak menuai kritik dan tinjauan dari beberapa sisi atau aspek dan akan berakibat pada aspek yang lainnya serta tidak mengabaikan aspek yang lainnya.

Teori pembelajaran yang paling dominan dan cukup lama bertenger dalam mempengaruhi proses pembelajaran di Indonesia adalah behavioristik. Teori ini menekankan atas pembelajaran yang merubah prilaku yang diamati dan terukur. Hal yang belum bisa diukur maka diabaikan. Teori ini diklaim tidak bertanggungjawab atas membina manusia yang sebenarnya justru akan melahirkan manusia mesin yang sifatnya mekanistik. Manusia yang terasingkan dari sifat kemanusiaan mencoba untuk memulai

\footnotetext{
${ }^{10}$ Mahdi, Ghuslani, Filsafat Sain Menurut Al Qur'anh. H. 4

${ }^{11}$ George, Ritzer, Sosiologi : Multiple Paradigm Science, h. 61
} 
keluar dari berbagai macam persepsi, maka dari sinilah muncul pembelajaran humanistik yang menekakan pada memanusiakan manusia.

Jika metode pembelajaran dirasa kurang mampu untuk merespon siswa untuk semangat belajar mandiri, maka perkembangan untuk mendorong siswa menguak ilmunya yaitu melalui pembelajaran kontruktivistik. Teori pembelajaran ini menekankan pada ide pengetahuan yang dikontruk bukan disuapi, ini artinya pembelajaran kurang berdaya dalam menumbuhkan kreativitas dan memperdayakan potensi lingkungan karena tidak menemukan hubungan yang jelas dan fungsional antara pengetahuan yang diperoleh disekolah dengan lingkungan, maka muncullah teori pembelajaran kontektual. Teori pembelajaran kotektual berupaya menemukan dan mengembangkan makna dan dibermaknakan (al Wasilah) ${ }^{12}$. Inilah teori pembelajaran yang sedang banyak diupayakan dan dikembangkan dan diterapkan pada akhir-akhir ini.

Pembelajaran yang santer pada saat ini adalah pembelajaran secara demokrasi. Suatu pembelajaran yang dielu-elukan oleh masyarakat karena pembelajaran terdahulu berlatar belakang masih adanya unsur kekerasan, penekanan, pemaksaan dan sifatnya teknis. Pembentukan pendidikan yang dilakukan secara sentralistik lebih specifik pada pembelajaran yang hanya mengagungkan pembentukan prilaku keseragaman pakaian, keseragaman kurikulum agar menghasilkan keteraturan ketertiban dan kepatuhan yang virusnya adalah paradigma sentralistik yang menghendaki sumbernya sama atau seragam.

Strategi pembelajaran yang menyeragamkan merupakan tindakan yang memposisikan sebagai pengingkaran terhadap keragaman. Teori ini merujuk pada pengembangan pembelajaran behavioristik yang menekankan stimulus-respon dalam proses belajar mengajar $^{13}$

Kritik dan nalar dalam teori pembelajaran di atas merupakan sebuah dinamika yang positif. Karena ada unsur untuk memperbaiki dan meningkatkan kualitas pendidikan dan pembelajaran. Tapi perlu adanya pertanyaan yang melekat bahwasanya mengapa prilaku kekerasan dan kekacauan tersebut hanya di pandang sebagai akibat dari pola penyeragaman ? mengapa tidak dilihat dari segi moral dan spiritualnya ? mengapa proses belajar mengajar yang bersifat mekanistis hanya di pandang model pembelajarannya ? mengapa tidak memandang dari paradigma filosofinya yang mendasarinya ? inilah akibat yang sangat menonjol sekali dari paradigma positivistik yan memperkenalkan melalaui

\footnotetext{
12 Johnson, Contextual Teaching dan Learning: Menjadikan Kegiatan belajar Mengajar Mengasikan dan Bermakna, h. 19

${ }^{13}$ Budiningsih, Belajar dan Pembelajaran, h. 2-5
} 
imperalisme Barat sehingga banyak menimbulkan dikotomi antara ilmu umum dengan ilmu agama. ${ }^{14}$ Teori pembelajaran yang diimport dari Barat seperti behavioristik, humanistik, kontruktivisme dan kognitif dan yang paling terakhir adalah pembelajaran kontektual dan kesemuanya itu merupakan penganut paradigma sekuler.

Pembelajaran yang kental dengan nilai-nilai dan makna adalah pembelajaran humanistik dan kontektual, akan tetapi kedua pembelajaran tersebut hanya berkisar pada kehidupan di dunia saja tidak pernah naik ke nilai-nilai ilahiyyah. Menurutnya alam telah merancang semuanya untuk menggabungkan pengetahuan dan tindakan ${ }^{15}$

Kehadiran paradigma tauid menemukan urgensi bagi pengembangan pembelajaran. Paradigma ini menghendaki agar seluruh entetitas baik di Bumi atau di Langit, ententitas empirik maupun ghoib terintegrasi secara seimbang dalam pengembangan teori dan praktek pembelajaran. Paradigma ini justru menempatkan ententitas Tuhan sebagai The Ultimate of Reality. Paradigma ini menghendaki agar para pendidik muslim mengkontruksi teori dan praktek pembelajarannya. Paradigma ini akan mampu menata ulang status keilmuan antara ilmu umum denga ilmu agama, sumber keilmuan, objek-objek keilmuan, klasifikasi keilmuan, metodologi keilmiahan, dan langkah-langkah integrasian ilmu agama dan ilmu umum.

Semangat pencairan paradigma Tauhid tersebut pada pembelajaran perlu mengembangkan menjadi prinsip-prinsip tersebut diantaranya : rahmaniyah (kasih sayang), takamuliyah (integratif), syumuliyah (komprehensif), tawzuniyah ( balance), istimroriyah ( continuity), wasaliyah ( kemediaan), rabbaniyah ( keterahan nilai ilahiyah ) dan uswiyah (keteladanan )

\section{E. Kesimpulan}

Paradigma Tauhid adalah upaya untuk menemukan urgensinya bagi pengembangan Ilmu Pengetahuan dengan sistem pembelajaran dalam pendidikan Islam. Paradigma ini menghendaki agar seluruh entetitas antara Bumi dan Langit, entetitas Empirik dan Ghaib, terintegrasi secara seimbang dalm pengembangan teori dan praktek pembelajaran.

Paradigma ini menempatkan etentitas Tuhan sebagai The Ultimate of Reality bukan al makhluk al faqir (makhluk yang bergantung). Teori ini menghendaki agar semua pendidik

\footnotetext{
${ }^{14}$ Mulyadi, Kertanegara, Integrasi Ilmu: Sebuah Rekontruksi Holistik, h. 20

15 Johnson, Contextual Teaching dan Learning: Menjadikan Kegiatan belajar Mengajar Mengasikan dan Bermakna, h. 50
} 
muslim merekontruksi teori dan praktek pembelajarannya. Paradigma ini akan menata ulang tentang status keilmuan antara ilmu umum dgn ilmu agama. Sumber keilmuan, dan objek-objek keilmuan, klasifikasi keilmuan, metodologi ilmiah dan langkah-langkah integrasi antara ilmu umum dan ilmu agama dapat di sinkronisasikan dalam kehidupan.

\section{Daftar Pustaka}

Abbs Mahmud, (1986) Filsafat Qur'an : filsafat, Spiritual dan Sosial dalam Isyarat al Qur'an, Jakarta: Pustaka Firdaaus

Budiningsih, Dr (2005), Belajar dan Pembelajaran, Jakarta : Rineka Cipta

Elaine, Johnson, (2009), Contextual Teaching dan Learning: Menjadikan Kegiatan belajar Mengajar Mengasikan dan Bermakna, Bandung : Mizan

George, Ritzer ( 1980), Sosiologi : Multiple Paradigm Science, Boston : Allyn and bacon. Kuntowijoyo, (1991), Paradigma Islam: Interpretasi Untuk Aksi, Bandung Mizan.

Mahdi, Ghuslani, (1990), Filsafat Sain Menurut Al Qur'an : Bandung Mizan

Mulyadi, Kertanegara (2005), Integrasi Ilmu: Sebuah Rekontruksi Holistik, Jakarta : UIN Press

Syamsuri S.A, (1989), Pengantar Teori Pengetahuan. Jakarta : Proyek Pengembangan Lembaga Pendidikan Tenaga Kependidikan DIKTI, DIKBUD

Verhaak, M Imam Haryono, (1989), Filsafat Ilmu Pengetahuan: Telaah Atas cara Kerja Ilmu-ilmu, Jakarta PT. Gramedia 